\title{
O Nível de Empatia de Participantes do Projeto de Extensão Universitária Sorriso de Plantão e sua Contribuição Para a Formação em Saúde
}

\author{
Maria Rosa da Silvaํ, Josineide Francisco Sampaio², Ewerton Amorim Santos³
}

\begin{abstract}
RESUMO
O Projeto de Extensão Universitária Sorriso de Plantão é formado por alunos de diversos cursos de Graduação, em sua maioria da área de saúde. Busca promover o bem-estar de crianças hospitalizadas, para dirimir a ociosidade e o estresse hospitalar. O objetivo é a identificação das competências e habilidades dos integrantes relacionados à empatia e a sua contribuição na formação profissional em saúde. Foi aplicado um questionário para conhecimento do perfil do grupo e utilizado o instrumento brasileiro validado Inventário de Empatia (IE), os dados tabulados em planilhas no Microsoft Excel 2010 e analisados por meio da estatística inferencial no programa SPSS. Foram investigados todos os palhaços doutores atuantes em cinco hospitais da cidade de Maceió/AL entre 2016 e 2017. Verifica-se que 51,6\% são menores de 21 anos e estão há mais de dois anos no projeto; $89,2 \%$ são estudantes da saúde e $84,9 \%$ de instituições públicas. Observa-se integrantes com elevada taxa de Tomada de Perspectiva (45,1); Altruísmo (31,3); Flexibilidade Interpessoal (31,3) e Sensibilidade Afetiva (37,9), abaixo em relação aos dados normativos de IE. Desse modo, o Projeto contribui com ensino desconstruído do tradicional e diferenciado, referente à empatia, valores, atitudes, relações humanas e formação profissional em saúde, tornando relevante a participação do aluno no período em que participa do projeto, aperfeiçoando ou mesmo desenvolvendo habilidade necessária para o futuro exercício profissional escolhido.
\end{abstract}

Palavras-chave: Extensão universitária. Formação profissional em saúde. Interdisciplinaridade. Empatia.

\section{THE LEVEL OF EMPATHY OF PARTICIPANTS OF THE PROJECT UNIVERSITY EXTENSION SORRISO DE PLANTÃO AND ITS CONTRIBUTION TO HEALTH TRAINING}

\begin{abstract}
The Sorriso de Plantão Extension University Project is formed by students from several undergraduate courses, mostly from the health area. It seeks to promote the well-being of hospitalized children, to solve idleness and hospital stress. The objective is the identification of the competences and abilities of the members related to empathy and its contribution in professional training in health. A questionnaire was applied to know the profile of the group and used the Brazilian instrument validated Empatia Inventory (IE), data tabulated in spreadsheets in Microsoft Excel 2010 and analyzed through inferential statistics in the SPSS program. All clown doctors working in 5 hospitals in the city of Maceió / AL were investigated between 2016/2017. It is verified that $51.6 \%$ are under 21 years and are more than two years in the project; $89.2 \%$ are health students and $84.9 \%$ are public institutions. It is observed members with high rate of Perspective Analysis $(45,1)$; Altruism $(31,3)$; Interpersonal Flexibility (31.3) and Affective Sensitivity (37.9) below in relation to IE normative data. Thus, the Project contributes with deconstructed teaching of traditional and differentiated, related to empathy, values, attitudes, human relations and professional training in health making relevant student participation in the period in which it participates in the project, improving or even developing the necessary ability to the future professional exercise chosen.
\end{abstract}

Keywords: University extension. Professional training in health. Interdisciplinarity. Empathy.

Recebido em: $14 / 9 / 2018$

Alterações requeridas em: 18/2/2019

Aceito em: 20/5/2019

\footnotetext{
Graduação em Enfermagem pela Universidade Federal de Alagoas. Mestrado em Ensino na Saúde pela Ufal. Doutoranda pelo Programa de Pós-Graduação em Saúde Pública pela Universidade de São Paulo. Possui experiência nas áreas de Pediatria, Ludoterapia, Palhaço de Hospital e educação em saúde. Docente da Universidade Estadual de Ciências da Saúde de Alagoas. enfamariarosa@yahoo.com.br

Graduação em Estudos Sociais pela Faculdade de Formação de Professores de Arapiraca. Especialização em Ciências Sociais e Mestrado em Sociologia pela Universidade Federal de Alagoas. Doutorado em Ciências na área de Saúde Pública pela Escola Nacional de Saúde Pública Sérgio Arouca - Ensp/Fiocruz (2013). Professora-adjunta com dedicação exclusiva na Faculdade de Medicina da Universidade Federal de Alagoas. Possui experiência na área de Sociologia Geral, atuando na área de Ciências Sociais Aplicadas à Saúde, Direito e Saúde e Direitos Humanos. josineide.sampaio@famed.ufal.br

3 Graduação em Nutrição pela Universidade Federal de Alagoas. Mestrado em Epidemiologia dos Agravos Nutricionais pela Faculdade de Nutrição da Ufal. Doutorando pelo Programa de Pós-Graduação em Ciências da Saúde da Universidade Federal de Sergipe. Possui experiência nas áreas de Metodologia, Epidemiologia, Bioestatística e Nutrição. Docente da Universidade Estadual de Ciências da Saúde de Alagoas. ewertonamorim@hotmail.com
} 


\section{INTRODUÇÃO}

Em consonância com a Política Nacional de Extensão Universitária, as Diretrizes Curriculares Nacionais (DCNs) para os cursos de Graduação na área de saúde compreendem que o aluno deve "aprender a aprender, que engloba aprender a ser, aprender a fazer, aprender a viver junto e aprender a conhecer, garantindo a capacitação de profissionais com autonomia e discernimento para assegurar a integralidade da atenção, a qualidade e a humanização do atendimento prestado aos indivíduos, famílias e comunidades"(BRASIL, 2001, p. 9).

Entre as competências e habilidades indicadas pelas DCNs como necessárias a serem desenvolvidas na formação dos profissionais na área da saúde, encontram-se: a) Tomada de Decisão, relacionada à capacidade de avaliar, sistematizar e decidir adequadamente, baseando-se em evidências científicas; b) Comunicação, refere-se à habilidade de manter acessível e manter a confiabilidade da confidencialidade das informações na interação com outros profissionais de saúde e o público em geral, pois envolve a comunicação verbal, não verbal, escrita, leitura e tecnologia de informação e c) Liderança no trabalho em equipe multiprofissional, relacionada à capacidade de assumir posições de liderança, tendo em vista o bem-estar da comunidade, o que envolve compromisso, responsabilidade e empatia, além de articular as habilidades e competências, anteriormente referidas, para atuar profissionalmente de forma efetiva e eficaz (BRASIL, 2001).

Outro ponto em comum refere-se ao perfil do profissional e do egresso, que deve reafirmar o caráter da responsabilidade social da universidade e atuar no sentido de contribuir com ações e propostas para o desenvolvimento, melhoria das condições de saúde, educação e sustentabilidade da comunidade de atuação (BRASIL, 2001).

Em 2002, ao tomar conhecimento do trabalho de um grupo de profissionais que se fantasiavam de palhaços doutores para visitar pacientes, uma estudante da Faculdade de Medicina da Universidade Federal de Alagoas (Famed/Ufal), resolveu adotar o método. Com base na quebra do estigma de que o hospital é um ambiente sombrio e triste, surgiu o Projeto de Extensão da Famed/Ufal Sorriso de Plantão, inspirado nas ideias dos palhaços doutores do Grupo "Doutores da Alegria", de São Paulo, coordenado por Wellington Nogueira e que desenvolve atividades desde 1991. O Projeto Sorriso de Plantão tem como objetivo trabalhar a "sorrisoterapia" em hospitais do município de Maceió. A princípio, o projeto era restrito aos alunos dos cursos da área de saúde da Ufal (Medicina, Enfermagem, Odontologia e Nutrição); o projeto aos poucos foi se abrindo para os acadêmicos de outros cursos e, posteriormente, para outras universidades. Essa abertura foi decorrente de uma concepção que tem como base a solidariedade e a interdisciplinaridade e estas independem da formação de quem a pratica (SILVA; SANDES, 2016).

Para Batista, Vilela e Batista (2015), a aprendizagem e a formação na extensão universitária se constituem em um processo interdisciplinar, educativo, cultural, científico e político, pelo qual se promove uma interação que transforma não apenas a universidade, mas também os setores sociais com os quais interage. Enfatizam os autores que a indissociabilidade do ensino e extensão possibilita ao estudante ser o protagonista de sua formação técnica, obtendo competências necessárias à atuação profissional e também de sua formação cidadã, em um processo que lhe permite reconhecer-se como agente de garantia de direitos e de deveres de transformação social.

Nesse sentido, entre essas competências e habilidades, a empatia é considerada uma importante habilidade requerida do profissional de saúde, exercendo influência sobre o bem-estar individual e social. Segundo Falcone (2008), a empatia tem sido compreendida como uma habilidade social com base em um modelo multidimensional, que corresponde à capacidade que uma pessoa tem de compreender, compartilhar ou considerar sentimentos, necessidades e perspectivas de alguém, bem como de expressar esta compreensão de forma que a outra pessoa se sinta validada e compreendida.

Observa-se que as habilidades constituídas pelos componentes cognitivos, afetivos e comportamentais da empatia estão relacionadas às habilidades e competências a serem desenvolvidas no processo de formação acadêmica, de acordo com a Política Nacional de Extensão Universitária, que tem como diretrizes: a) Interação Dialógica, que compreende uma relação de interação e de troca de saberes entre a universidade e a sociedade, na qual os saberes são construídos em sua prática cotidiana, no fazer profissional e na vivência comunitária; b) Interdisciplinaridade $e$ Interprofissionalidade, a partir da interação de modelos, conceitos e metodologias de diversas disciplinas e áreas de conhecimento e pelas alianças intersetoriais e interprofissionais; c) Impacto na Formação do Estudante, pela ampliação de referências e experiências diretas que fortalecem compromissos éticos e solidários (FORPROEX, 2012). 
Nesse sentido, a extensão universitária fortalece a articulação da teoria com a prática em outros cenários de aprendizagem, além da sala de aula, e valoriza a formação geral, humanista, crítica, reflexiva e ética.

Ao considerar as habilidades e competências a serem desenvolvidas no processo de formação em saúde requeridas na Política Nacional de Extensão e nas Diretrizes Curriculares Nacionais, o presente estudo teve como objetivo identificar o nível de empatia nos participantes do Projeto de Extensão Universitária Sorriso de Plantão e a sua contribuição na formação profissional.

\section{MATERIAL E MÉTODO}

\section{Tipo de Estudo}

Trata-se de um estudo descritivo, transversal de abordagem quantitativa, de amostragem censitária.

\section{Cenário}

O Projeto de Extensão Universitária Sorriso de Plantão, vinculado à FUFAL, Famed/Ufal, em parceria com a Universidade Estadual de Ciências da Saúde de Alagoas (Uncisal), tem como objetivo promover o bem-estar de crianças hospitalizadas, visando a diminuir a ociosidade, aliviar a dor e o sofrimento por meio do acolhimento e atividades lúdicas interativas que permitem vivenciar experiências peculiares à infância que foram interrompidas pelo tratamento hospitalar. Ademais, visa a promover uma formação humanizada que utiliza a figura do palhaço doutor, caracterizado com jaleco, adereços coloridos e nariz de palhaço, com a função de gerar momentos de alegria e entretenimento ao público por meio de suas atitudes engraçadas e de seu modo diferente de se vestir, levando a criança para o universo da fantasia (SILVA; SANDES, 2016).

As atividades do projeto são de caráter interdisciplinar e multiprofissional desenvolvidas por alunos dos cursos de Administração, Direito, Educação Física, Enfermagem, Engenharia Civil, Fisioterapia, Fonoaudiologia, Medicina, Nutrição, Pedagogia, Terapia Ocupacional e Licenciatura em Letras-Libras.

Nesse sentido, o trabalho em equipe é desenvolvido fundamentado na reflexibilidade, comunicação e interação dialógica, tendo em vista a atenção integral ao usuário hospitalizado. As atividades ocorrem semanalmente nos hospitais: Clínica Infantil Dayse Breda, Hospital Escola Prof. Hélvio Auto, Hospital Geral do Estado, Hospital Universitário Prof. Alberto Antunes e Hospital Santa Casa de Misericórdia de Maceió - Unidade Farol.

\section{Participantes}

Participaram do estudo $100 \%$ (93) dos integrantes do Projeto Sorriso de Plantão no ano letivo 2016/2017, de Instituições de Ensino Superior da cidade de Maceió (AL).

A coleta de dados foi realizada por meio da aplicação de questionários durante reunião mensal do Projeto, em dezembro de 2016, após a apresentação dos objetivos da pesquisa e da leitura e assinatura do Termo de Cconsentimento Llivre e Eesclarecido (TCLE). O primeiro questionário aplicado foi para caracterizar os sujeitos da pesquisa, contendo variáveis sobre: sexo, idade, área de formação, instituição de origem, período do curso, ano de inserção no projeto e hospital onde atua. $O$ segundo foi o Inventário de Empatia descrito por Falcone et al. (2008), composto por 4 fatores que correspondem aos componentes da empatia: Tomada de Perspectiva, Flexibilidade Interpessoal, Altruísmo e Sensibilidade Afetiva.

O primeiro fator do Inventário de Empatia descreve a Tomada de Perspectiva, que avalia a motivação e a capacidade de compreender a perspectiva e o sentimento do outro (12 itens). O segundo fator avalia a Flexibilidade Interpessoal, que expressa a capacidade de aceitar e entender os pontos de vista diferentes (10 itens). O terceiro avalia o Altruísmo, que identifica se há sacrifício de seus próprios interesses a favor do outro (9 itens). No quarto e último fator avalia-se a Sensibilidade Afetiva, descrito pelos autores como sentimento de compaixão e de interesse pelo estado emocional do outro ( 9 itens). A resposta de cada item classifica-se de 1 a 5, em escala tipo Likert, de acordo com a frequência dos comportamentos descritos, variando de nunca (1), raramente (2), regularmente (3), quase sempre (4) e sempre (5). Dos 40 itens que compõem o Inventário de Empatia, entretanto, 17 são reversos $(3,4,5,8,9,13,16,19,20,22,24,26,30,32$, 35,38 e 40 ), os quais foram invertidos para obtenção do escore final.

\section{Análise dos Dados}

Utilizou-se o Microsoft Office Excel 2010 para tabulação dos dados e o software SPSS, versão 21, para análise. A amostra foi descrita por meio de tabelas de distribuição de frequências e os fatores de empatia, por meio de medidas de tendência central e dispersão. Realizou-se o cálculo do Alfa de Cronbach para verificação da confiabilidade da existência de diferenças significativas entre os gêneros associados às variáveis, mensurou-se a média das correlações entre os itens do instrumento, considerando 0,7 aceitável. Utilizou-se o 
teste de Mann-Whitney e Kruskal-Wallis, respeitando a distribuição não paramétrica dos dados, verificada pelo teste de Kolmogorov-Smirnov. Diferenças foram consideradas estatisticamente significativas quando $\mathrm{p}$ $<0,05$, para um Intervalo de Confiança de $95 \%$.

\section{Aspectos Éticos}

O presente estudo foi aprovado pelo Comitê de Ética e Pesquisa da Ufal, sob o parecer de no.1.869.742.

\section{RESULTADOS E DISCUSSÕES}

\section{Caracterização da Amostra}

Identificou-se o perfil dos participantes do Projeto de Extensão Sorriso de Plantão por meio de aplicação de questões relacionadas às variáveis de sexo, idade, área de formação, instituição de origem, período do curso, ano de inserção no projeto e hospital em que atuavam.

Tabela 1 - Característica dos participantes do Projeto de Extensão Sorriso de Plantão, 2016

\begin{tabular}{|c|c|c|c|}
\hline Variáveis & Categorias & $\begin{array}{l}\text { Número de } \\
\text { Participante }\end{array}$ & Porcentagem \\
\hline \multirow[t]{2}{*}{ Sexo } & Masculino & 23 & 24.7 \\
\hline & Feminino & 70 & 75.3 \\
\hline \multirow[t]{2}{*}{ Idade } & $\leq 21$ & 48 & 51.6 \\
\hline & $>21$ & 45 & 48.4 \\
\hline $\begin{array}{l}\text { Ano de } \\
\text { inserção }\end{array}$ & $\leq 2016$ & 48 & 51.6 \\
\hline no projeto & > 2016 & 45 & 48.4 \\
\hline Hospital & CIDB & 12 & 12.9 \\
\hline \multirow[t]{4}{*}{ que atua } & HEHA & 13 & 14.0 \\
\hline & HGE & 36 & 38.7 \\
\hline & HUPAA & 20 & 21.5 \\
\hline & SANTA CASA & 12 & 12.9 \\
\hline Área de & Humanas & 09 & 9.7 \\
\hline \multirow[t]{2}{*}{ Formação } & Saúde & 83 & 89.2 \\
\hline & Exatas & 01 & 1.1 \\
\hline \multirow[t]{3}{*}{ Período } & $<60$ & 38 & 40.9 \\
\hline & $\geq 60$ & 53 & 57.0 \\
\hline & Formados & 02 & 2.2 \\
\hline $\begin{array}{l}\text { Instituição } \\
\text { de origem }\end{array}$ & $\begin{array}{l}\text { Particular } \\
\text { Pública }\end{array}$ & $\begin{array}{l}14 \\
79\end{array}$ & $\begin{array}{l}15.1 \\
84.9\end{array}$ \\
\hline
\end{tabular}

CIDB: Clínica Infantil Dayse Breda; HEHA: Hospital Escola Prof. Hélvio Auto; HGE: Hospital Geral do Estado; HUPPA: Hospital Universitário Prof. Alberto Antunes e Santa Casa: Hospital Santa Casa de Misericórdia de Maceió.

Fonte: Dados da pesquisa.
Observa-se que $75,3 \%$ dos participantes do projeto são do sexo feminino. Segundo Rufinoni (2015), o número de mulheres que ingressam no Ensino Superior é maior do que o de homens. O percentual médio de ingresso de alunas até 2013 foi de $55 \%$ do total, em cursos de Graduação presenciais. Se o recorte for feito por concluintes, o índice sobe para $60 \%$.

Nota-se que $48,4 \%$ dos integrantes permanecem no projeto por mais de um ano. Isso pode estar relacionado ao estabelecimento de vínculos entre os participantes e o reconhecimento de que as atividades do projeto contribuem para sua formação e atuação profissional. Segundo Porto, Bittencourt e Sampaio (2015), o respeito ao outro, o diálogo, o aprender, o escutar e o acolhimento no interior dos projetos de extensão são aspectos valorizados pelos participantes, além das relações sociais externas. No estudo de Porto (2017) também se identificou que os alunos se sentem motivados a participar dos projetos de extensão porque os conhecimentos adquiridos são aplicados dentro e fora da universidade, possuindo alto impacto na qualificação, formação e atuação profissional.

Em relação à participação dos integrantes do projeto nos hospitais, é importante informar que a distribuição ocorre considerando a quantidade de leitos e o perfil dos pacientes a serem atendidos. No caso do HGE, 38,7\% dos participantes do Projeto Sorriso de Plantão atuam nesse hospital por contar com uma média de 90 crianças hospitalizadas, distribuídas nos setores de observação, internamento, Unidade de Terapia Intensiva (UTI) e setor de queimados.

O segundo local com maior número, $21,5 \%$, é o Hupaa. Esse hospital atende uma grande quantidade de usuários, de todas as faixas etárias, e possui cerca de 160 leitos de internação. Para atender essa quantidade de usuários com perfis específicos, os palhaços doutores são distribuídos nos diversos setores, desenvolvendo diferentes atividades, de acordo com as características e a situação de saúde dos usuários na clínica médica e cirúrgica. Por exemplo, enquanto um grupo permanece no setor de pediatria, outra parte da equipe visita adultos hospitalizados no setor de nefrologia.

Quanto à área de formação dos participantes, percebe-se que a maioria é da área da saúde, com $89,2 \%$, destacando-se os do curso de Medicina (21), Terapia Ocupacional (19), Fisioterapia (19) e Enfermagem (13). A maior participação de estudantes da área de saúde pode estar relacionada à oportunidade de ter acesso ao ambiente hospitalar e contato com os usuários, além do interesse em desenvolver habilida- 
des inerentes ao perfil profissional que gostariam de ter, que são requeridas e estimuladas no decorrer das atividades de extensão universitária (PORTO, 2017).

Nesse sentido, novas propostas de formação para a área de saúde vêm sendo instituídas com o objetivo de formar profissionais com visão crítica-reflexiva, utilizando como estratégia de trabalho a integração da equipe multiprofissional, a delimitação de clientela, a criação de vínculo, a elaboração de projetos terapêuticos singulares conforme a necessidade de cada caso e a ampliação dos recursos de intervenção sobre o processo saúde/doença (BRASIL, 2006).

Considerando qual deva ser a visão ampliada do cuidar, participam também do Projeto de Extensão Sorriso de Plantão alunos das áreas de Humanas, com 9,7\% (Psicologia, Direito, Administração, Letras e Pedagogia) e Exatas com 1\%, (Engenharia Civil), que integram as equipes interdisciplinar e multiprofissional, permitindo a ampliação da atenção individual e coletiva, possibilitando que aspectos afetivos, emocionais e sociais do usuário, e não apenas os biológicos, sejam compreendidos e trabalhados pelos futuros profissionais de saúde (BRASIL, 2009; CUNHA, 2010).

Segundo Correia, Taveira e Freitas (2015), é necessário maior investimento curricular nas Ciências Sociais, Humanas, Artes e Literatura. Estas áreas do conhecimento, associadas ao estudo disciplinar, possibilitam o desenvolvimento de uma melhor relação com os sujeitos. Além disso, a interdisciplinaridade implica uma consciência dos limites e potencialidades de cada campo do saber, para que possa haver uma abertura em direção de um fazer coletivo (SALES et al., 2011).

Neste estudo, um maior número de participantes encontra-se a partir do 60 período (57\%). Em estudo realizado por Porto (2017) sobre a extensão universitária, observa-se que nesse momento do curso o estudante possui maior conhecimento sobre as atividades ofertadas na sua instituição e procuram se engajar naquelas que possibilitam adquirir ou potencializar conhecimentos e experiências relacionadas ao que pretendem desenvolver como profissionais.

Também pode-se observar que $40,9 \%$ dos participantes do Projeto de Extensão Sorriso de Plantão encontram-se em períodos anteriores ao 60 período do curso que estão inseridos. Segundo Martins, Maciel e Padilha (2015), a variedade enriquece o grupo, pois o aluno mais novo está ansioso por se aproximar da prática e tem sede de conhecimento; e o mais experiente já possui tranquilidade para lidar com as atividades e é capaz de auxiliar, orientando os mais novos. Essa integração entre colegas que possuem interesses semelhantes, mas em diferentes fases de Graduação, provoca uma visualização holística da atuação profissional e acadêmica, devido ao contato com essas diferentes fases.

Ribeiro (2005) e Caldas et al. (2012) ressaltam a importância da atuação dos alunos desde o início do curso por incentivar a busca de conhecimentos para sanar as necessidades da comunidade, o que possibilita uma formação profissional humanística. Segundo Rossoni e Lampert (2004), os discentes devem ser inseridos o quanto antes na extensão universitária, atendendo ao novo perfil do profissional de saúde exigido pelas DCNs. Nesse sentido, percebe-se que a extensão possibilita o desenvolvimento de habilidades e competências relacionadas aos princípios das DCNs que norteiam a formação, como o fortalecimento e a articulação da teoria com a prática, permitindo a criação de projetos pedagógicos inovadores e adequados à realidade e às necessidades de saúde da população (PEREIRA; LOPES; LUGARINHO, 2006).

É relevante citar que 2,1\% correspondem a dois alunos que se formaram e continuam no projeto, embora estejam fazendo Pós-Graduação, um deles no Mestrado no curso de Direito, e o outro no Doutorado de Letras, ambos na Ufal. Em estudo desenvolvido por Almeida et al (2007), observa-se que os discentes permanecem nos projetos de extensão porque acreditam em um aprendizado coletivo, dialógico e libertador.

Em relação às Instituições de Ensino Superior a que pertencem os participantes do projeto, percebe-se que $84,9 \%$ são de instituições públicas. Este quantitativo pode estar relacionado ao tempo de vigência do Projeto nas duas maiores instituições públicas formadoras em saúde do Estado de Alagoas (Ufal e Uncisal), nas quais há maior divulgação das ações desenvolvidas, em que os alunos compartilham nos corredores as experiências vivenciadas no projeto e nas redes sociais das quais participam. Segundo o estudo realizado por Porto (2017), a maioria dos alunos afirmou que obtiveram informações e direcionamentos sobre as ações extensionistas ofertadas por meio do relato das experiências daqueles que participam ou participaram dessas ações e das redes sociais.

A Tabela 2 apresenta dados desta pesquisa utilizando como referência os dados normativos do Inventário de Empatia (IE) de Falcone et al. (2008), por serem considerados adequados em diferentes grupos e contextos sociais da população brasileira, para aferir os níveis de empatia. 
Tabela 2 - Avaliação da Empatia dos participantes do Projeto Sorriso de Plantão, 2016

\begin{tabular}{ccccccc}
\hline Variáveis & Média & Desvio padrão & Mínimo & Máximo & Falcone ${ }^{a}$ & Alpha de Cronbach \\
\hline TP & 45,1 & 8,1 & 15,0 & 60,0 & 40,92 & 0,883 \\
FI & 31,3 & 7,3 & 9,0 & 50,0 & 31,08 & 0,847 \\
AL & 31,3 & 5,3 & 12,0 & 41,0 & 22,46 & 0,675 \\
AS & 37,9 & 5,6 & 9,0 & 45,0 & 43,92 & 0,809 \\
\hline
\end{tabular}

a Dados normativos segundo Falcone 2008.

Fonte: Dados da pesquisa.

Observa-se na Tabela 2 que os integrantes do Projeto Sorriso de Plantão apresentaram uma média de 45,1 para o Fator TP, considerada elevada em relação aos dados normativos de 40,92 apresentada para o IE. Referente à Flexibilidade Interpessoal (FI) corresponde a níveis de 31,3 , assemelhando-se à média de 31,08 para IE. Quanto aos componentes afetivos: AL apresenta 31,3; valor superior aos dados normativos do IE, de 22,46, enquanto no componente SA foi apresentado 37,9; considerado inferior à referência de 43,92.

Percebe-se que os participantes do Projeto de Extensão Sorriso de Plantão, de um modo geral, apresentaram valores dentro dos dados normativos indicados por Falcone et al. (2008), embora tenham apresentado diferenças nos fatores como TP e AL com médias elevadas e médias mais baixas para $\mathrm{FI}$ e SA, tendo como referência o IE. Segundo a autora, entretanto, a média encontrada em um fator não é suficiente para afirmar se o participante tem ou não empatia, pois esta implica algum nível de sentimento e cognição relacionados aos diferentes fatores que a compõem.

Observa-se na Tabela 2 que Alpha de Cronbach referente aos itens que correspondem ao fator Altruísmo apresentou valor de 0,67, menor que 0,7 . Segundo Bland e Altman (1997), esse resultado pode estar associado à quantidade e ao perfil dos sujeitos que compuseram a amostra correlacionando aos dados do IE.

Para ampliar a análise sobre o nível de empatia nos participantes do projeto, observou-se cada fator que a compõe segundo os hospitais nos quais atuam os estudantes do sexo masculino e do feminino do Projeto de Extensão Sorriso de Plantão.

Segundo o IE de Falcone et al. (2008), TP é o primeiro fator a ser avaliado, considerado um componente cognitivo da empatia. Ele se caracteriza por não implicar experimentar os mesmos sentimentos da outra pessoa, mas, sim, experimentar um entendimento

Tabela 3 - Avaliação da Empatia quanto ao Fator Tomada de Perspectiva (TP) dos participantes do Projeto de Extensão Sorriso de Plantão, segundo os hospitais onde atuam, 2016

\begin{tabular}{|c|c|c|c|c|c|c|c|c|}
\hline Variável & $\mathrm{Ca}$ & egorias & Média & $\begin{array}{l}\text { Desvio } \\
\text { padrão }\end{array}$ & Mínimo & Máximo & Falcone ${ }^{a}$ & $\mathbf{p}^{1}$ \\
\hline \multirow{10}{*}{ Hospital } & DAYSE & Masculino & 51 & - & 51 & 51 & 41,21 & \multirow{2}{*}{0,884} \\
\hline & BREDA & Feminino & 48,5 & 7,1 & 37 & 59 & 40,45 & \\
\hline & \multirow{2}{*}{ HEHA } & Masculino & 42,2 & 2,8 & 39 & 45 & & \multirow{2}{*}{0,883} \\
\hline & & Feminino & 41,1 & 8,7 & 26 & 54 & & \\
\hline & \multirow{2}{*}{ HGE } & Masculino & 42,9 & 8,8 & 32 & 56 & & \multirow{2}{*}{0,246} \\
\hline & & Feminino & 46,9 & 8,1 & 24 & 60 & & \\
\hline & \multirow{2}{*}{$\mathrm{HU}$} & Masculino & 42 & 8,5 & 29 & 52 & & \multirow{2}{*}{0,63} \\
\hline & & Feminino & 44,2 & 6,7 & 28 & 53 & & \\
\hline & \multirow{2}{*}{ SANTA CASA } & Masculino & 37,8 & 14,3 & 15 & 49 & & \multirow{2}{*}{0,033} \\
\hline & & Feminino & 49 & 3,6 & 43 & 52 & & \\
\hline
\end{tabular}

a Dados normativos segundo Falcone 2008; ${ }^{1}$ Teste de Mann-Whitney. 
do que é sentido por ela, que envolve neutralidade e imparcialidade daquele que empatiza. Trata-se de uma compreensão acurada dos sentimentos e pensamentos dos outros. Araújo (2008) afirma que a TP corresponde à capacidade de entender a perspectiva e sentimentos de outra pessoa, principalmente em situações nas quais ocorre conflitos de interesse, e que o indivíduo, com elevado nível deste fator, é motivado a compreender o ponto de vista da outra pessoa, nos termos desta, antes de expressar a própria perspectiva.

Observa-se na Tabela 3 que a maioria dos integrantes do Projeto Sorriso de Plantão demonstra ter o Fator TP elevado. É destacado que altos índices de TP consistem em ser sensível às características únicas de cada paciente (FALCONE et al., 2008). Constata-se que houve pouca variação no desvio padrão com relação aos integrantes dos hospitais, com exceção para o participante do sexo masculino que atua na Santa Casa. Também foi nesse grupo que ocorreu uma diferença significativa $(p / 0,003)$ entre os sexos masculino e feminino.

Eliot (2013) identifica o sexo feminino como mais empático por expressar seus sentimentos diante do outro. $\mathrm{O}$ sexo que demonstra com facilidade a emoção torna mais fácil se relacionar e perceber o outro. A empatia é o oposto polar da agressão, que a autora considera ser mais evidente nos homens. As mulheres tendem a ser influenciadas pelo desejo de parecerem bondosas e os homens pelo desejo de parecerem durões. Também argumenta que as mulheres foram criadas para cuidar e que a sociedade vem educando há anos para esta finalidade. A experiência de ser cuidadora do outro influencia na sensibilidade emocional e nas respostas neurais, tornando a mulher mais empática.

Segundo Ferreira (2010, p. 493), a palavra maternidade vem "do latim medieval maternitate, condição de mãe", como uma cultura incitada desde tenra idade que ensina que a mulher deva ser cuidadora, maternal e obediente, tornando essa ideia muito forte e constituindo um dos fatores que influenciou o resultado apresentado.

A argumentação de Pinker (2010) para a importância dos extremos nas explicações das diferenças sexuais está fundamentada na Teoria de Empatia-Sistematização (BARON-COHEN, 2004). De acordo com essa teoria, empatia e sistematização são extremos de um continuum e determinam o campo de maior habilidade de processamento do cérebro. De um lado, a facilidade em apreender pessoas e reconhecer emoções, e a empatia como característica preponderante no sexo feminino; do outro, a habilidade em processar objetos e identificar sistemas, e a sistematização (busca por regras e padrões de funcionamento de mecanismos) como marca de cérebros masculinos.

Com esse embasamento, a referida autora demonstra a maior frequência de mulheres no sentido empático do continuum, enquanto ela destaca o extremo da sistematização na síndrome de Asperger e sua consequente maior incidência em homens. Enfatiza as vantagens que cérebros empáticos garantem às mulheres, como a facilidade em reconhecer emoções e agir conforme as necessidades daqueles que as expressam, destreza em interações sociais, etc. Pesquisas apontam para a maior frequência de mulheres em empregos relacionados ao cuidado alheio, como exemplo a Psicologia, Medicina e Enfermagem (INEP, 2009).

Na Tabela 3, o sexo feminino apresentou altos índices de TP. Tanto o HGE, HU, HEHA e Dayse Breda têm amostragem elevada, com diferenciação para o Hospital Santa Casa apenas com relação à TP menor no sexo "masculino", o que justifica a predominância da TP no sexo feminino nas instituições citadas. HEHA e Dayse Breda, entretanto, apresentam dados femininos elevados em relação à média; mas apresentaram, no sexo masculino, surpreendente valor de TP em relação ao feminino, embora deva ser observada a inexistência de desvio padrão por representar um único participante.

Dando continuidade à avaliação do IE, a Tabela 4 apresenta os valores quanto ao Fator de Flexibilidade Interpessoal (FI). Esse fator complementa a avaliação cognitiva dos participantes.

Segundo Falcone et al. (2008), Fl avalia a capacidade de regular a própria perspectiva que permite modular a emoção envolvida na preocupação com o outro. Segundo Araújo (2008), neste contexto de profissionais de saúde, considera-se a FI como a capacidade em aceitar perspectivas, crenças e valores muito diferentes, além de tolerância à frustração provocada pela atitude do interlocutor, afirmando que pessoas com elevado nível em $\mathrm{Fl}$ "tendem a fazer menos julgamentos e críticas e sabem regular a sua própria emoção"; com baixo nível "indica rigidez para aceitar pontos de vista diferentes ou intolerantes, frente a comportamentos que provoquem frustração" (ARAÚJO, 2008, p. 63).

Na Tabela 4, o sexo masculino apresentou valores abaixo da média para o FI nos hospitais: $\mathrm{HGE}$, HU, HEHA e Clínica Infantil Dayse Breda, contudo os integrantes da Santa Casa apresentaram a maior média (36) para o gênero masculino em relação ao Dayse Breda (25), que apresentou o menor valor do padrão 
Tabela 4 - Avaliação da Empatia quanto ao Fator Flexibilidade Interpessoal (FI) dos participantes do Projeto de Extensão Sorriso de Plantão, segundo os hospitais onde atuam, 2016

\begin{tabular}{|c|c|c|c|c|c|c|c|c|}
\hline Variável & Cate & rias & Média & Desvio padrão & Mínimo & Máximo & Falcone ${ }^{\mathbf{a}}$ & $p^{1}$ \\
\hline \multirow{10}{*}{ Hospital } & \multirow{2}{*}{ DAYSE BREDA } & Masculino & 25 & - & 25 & 25 & 31,06 & \multirow{2}{*}{0,187} \\
\hline & & Feminino & 32,3 & 7,1 & 14 & 43 & 31,10 & \\
\hline & \multirow{2}{*}{ HEHA } & Masculino & 31,6 & 6,1 & 25 & 40 & & \multirow{2}{*}{0,883} \\
\hline & & Feminino & 29,9 & 9,7 & 11 & 39 & & \\
\hline & \multirow{2}{*}{ HGE } & Masculino & 25,3 & 7,6 & 13 & 36 & & \multirow{2}{*}{0,123} \\
\hline & & Feminino & 30,6 & 8 & 9 & 43 & & \\
\hline & \multirow{2}{*}{$\mathrm{HU}$} & Masculino & 30,8 & 8 & 19 & 41 & & \multirow{2}{*}{0,628} \\
\hline & & Feminino & 32,9 & 3,8 & 27 & 39 & & \\
\hline & \multirow{2}{*}{ SANTA CASA } & Masculino & 36 & 8,3 & 29 & 50 & & \multirow{2}{*}{0,807} \\
\hline & & Feminino & 34,4 & 5,1 & 30 & 45 & & \\
\hline
\end{tabular}

a Dados normativos Falcone 2008; ${ }^{1}$ Teste de Mann-Whitney.

Fonte: Dados da pesquisa.

do IE registrado $(31,8)$. No sexo feminino a maioria dos hospitais apresentou valores acima da média para o $\mathrm{FI}$, diferenciando a situação o HGE $(30,6)$ e o HEHA $(29,9)$.

O perfil das crianças hospitalizadas e acompanhadas pelo projeto pode favorecer este fator de empatia, em que os integrantes dos hospitais Santa Casa e Hupaa têm em comum o contato prolongado com a criança no processo de hospitalização, porque a permanência de internação entre idas e vindas da mesma criança é constante. Diferente do Dayse Breda, HGE e HEHA, os quais apresentam maior rotatividade do processo de internação que, em média, não têm seus usuários em longos períodos.

No Hospital Santa Casa as crianças assistidas têm uma prevalência de diagnóstico oncológico; com isso, a criança permanece hospitalizada num período estendido; isso interfere em diversos aspectos da vida do paciente e da família, criando vínculo com o palhaço doutor. No Hupaa o palhaço doutor consegue oferecer atendimento diferenciado em virtude de assistir crianças e adultos de variadas patologias, com destaque para crianças com doenças crônicas degenerativas e adultos em tratamento de hemodiálise. Dessa forma, o contato é constante com o mesmo usuário e seus familiares. Segundo Silva e Romeiro (2016), estes espaços tornam-se mais sensíveis e favoráveis para estabelecimentos de vínculos afetivos na relação paIhaço doutor e criança hospitalizada diante do cenário vivenciado.

De acordo com Oliveira (2012), este elo afetivo chama-se Topofilia, que é a relação entre pessoa e lugar ou ambiente físico, classificado como relação topofílica ou topofóbica. A percepção é colocada no cerne das preocupações geográficas. Há uma relevância dos sentidos dos homens, suas sensações e seus sentimentos, seus sonhos e seus anseios. $O$ valor atribuído ao meio está vinculado ao interesse e necessidade, porque a humanidade para viver e sobreviver precisa atribuir um valor ao mundo.

Diante das necessidades de acolhimento, escuta e gravidade da patologia, percebe-se nos dados anteriores que os palhaços doutores desenvolvem habilidades empáticas para atender. É preciso que a equipe crie maneiras diferenciadas de perceber e sentir a criança, desenvolvendo uma forma autêntica e um vínculo de confiança com a criança e seu familiar, valorizando a individualidade e intersubjetividade em cada caso.

Quanto à relação profissional x paciente, o lado afetivo deste último pode interferir na percepção de satisfação sobre a competência do profissional. Para que o profissional de saúde conquiste confiança e credibilidade por parte do usuário, faz-se necessário que ele leve em consideração o paciente integralmente e não apenas um corpo doente (PORTO; BITTENCOURT; SAMPAIO, 2015), vivenciando experiências práticas que consideram as pessoas em suas necessidades de saúde como sujeitos e não como objetos; tendo a percepção do ser como um sujeito único e singular (CUNHA, 2010). Assim, como preconizam as DCNs para a formação dos profissionais da área de saúde: "Garantindo a capacitação de profissionais com autonomia e discernimento para assegurar a integralidade 
Tabela 5 - Avaliação da Empatia quanto ao Fator Altruísmo (AL) dos participantes do Projeto de Extensão Sorriso de Plantão, segundo os hospitais onde atuam, 2016

\begin{tabular}{|c|c|c|c|c|c|c|c|c|}
\hline Variável & Catego & & Média & Desvio padrão & Mínimo & Máximo & Falconea & $\mathbf{p}^{1}$ \\
\hline \multirow{10}{*}{ Hospital } & \multirow{2}{*}{ DAYSE BREDA } & Masculino & 27 & - & 27 & 27 & 21,65 & \multirow{2}{*}{0,243} \\
\hline & & Feminino & 31,1 & 6,9 & 13 & 38 & 23,64 & \\
\hline & \multirow{2}{*}{ HDT } & Masculino & 29 & 5,6 & 22 & 34 & & \multirow{2}{*}{0,658} \\
\hline & & Feminino & 31,8 & 4 & 25 & 37 & & \\
\hline & \multirow{2}{*}{ HE } & Masculino & 28,9 & 4,6 & 21 & 34 & & \multirow{2}{*}{0,142} \\
\hline & & Feminino & 31,7 & 6,2 & 12 & 40 & & \\
\hline & \multirow{2}{*}{$\mathrm{HU}$} & Masculino & 32 & 4,5 & 25 & 37 & & \multirow{2}{*}{0,273} \\
\hline & & Feminino & 30,7 & 3,6 & 24 & 40 & & \\
\hline & \multirow{2}{*}{ SANTA CASA } & Masculino & 34,2 & 7 & 24 & 41 & & \multirow{2}{*}{0,679} \\
\hline & & Feminino & 33,3 & 3,2 & 27 & 36 & & \\
\hline
\end{tabular}

a Dados normativos segundo Falcone 2008; 'Teste de Mann-Whitney.

Fonte: Dados da pesquisa.

da atenção e a qualidade e humanização do atendimento prestado aos indivíduos, famílias e comunidades" (CUNHA, 2010, p. 4).

Para a Tabela 5 foi avaliado um dos fatores da empatia voltado para a emoção. Este fator foi relevante para a avaliação porque apresentou valores acima da média em todos os participantes do projeto.

Falcone et al. (2008) está em concordância com Batson (1997, p. 322) ao definir Altruísmo (AL) como "a ajuda com intenção de auxiliar outra pessoa sem expectativa de qualquer compensação (senão o bom sentimento resultante)". Para Araújo (2008), trata-se da capacidade de sacrificar por curto tempo as próprias necessidades em benefício de outra pessoa. Em relação ao fator $\mathrm{AL}$, a referida pesquisa apresenta este fator elevado em todos os integrantes do Projeto de Extensão Sorriso de Plantão, tanto no sexo feminino como no masculino, com variações de 27 a 34,2, em que a média da população medida pelo IE é de 22,46.

Entre os objetivos do Projeto de Extensão Sorriso de Plantão está o desenvolvimento do comportamento altruísta. Este objetivo é plenamente alcançado quando a média resultante foi considerada alta. Ser "altruísta" é projetar uma das características primordiais para o desenvolvimento do trabalho dos palhaços doutores (SILVA; SANDES, 2016). Tornam-se satisfatórios os dados da pesquisa por comprovarem que os integrantes apresentam as características propostas pelo projeto, em que a satisfação de doar-se é compensada pelo retorno do sentimento de contribuir para o bem-estar do outro. A motivação altruísta é "geradora de avaliação de custos e benefícios" que estão "envolvidos na decisão de ajudar" (FALCONE et al., 2008).

Hamamoto Filho (2011) apresentou uma amostragem resultante de um questionário aplicado entre os participantes do "Projeto Pronto Sorriso", em Goiás, e, como resultado, em $39,6 \%$ foi percebido o sentimento de realização pessoal. Para $41,5 \%$, havia o entendimento de que a ação desenvolvida pelo grupo era de atividade altruísta. Isso revela um comportamento que é ao mesmo tempo hedonista e humanitário. As DCNs orientam a formação dos profissionais e buscam romper com o paradigma do modelo biomédico, hospitalocêntrico e fragmentado; também apontam para novos métodos de ensino para formar profissionais com perfil diferenciado, com capacidade crítica, reflexiva e atitudes humanizadas (GONTIJO; SENNA; FERREIRA, 2012). Nessa lógica, projetos de extensão, como o Sorriso de Plantão, vinculados diretamente à saúde, colaboram para a formação e a humanização dos futuros profissionais com o perfil que as DCNs preconizam.

Na condição de projeto de extensão, permite refletir sobre os aspectos que necessitam ser observados para aprimorar as habilidades e competências quanto à formação do profissional em saúde no decorrer das atividades desenvolvidas.

Para finalizar a avaliação geral do IE, a Tabela 6 vai demonstrar os dados encontrados no fator de SA dos participantes do projeto, apresentando o lado afetivo dos pesquisados. 
Tabela 6 - Avaliação da Empatia quanto ao Fator Sensibilidade Afetiva (SA) dos participantes do

Projeto de Extensão Sorriso de Plantão, segundo os hospitais onde atuam, 2016

\begin{tabular}{|c|c|c|c|c|c|c|c|c|}
\hline Variável & Cate & orias & Média & Desvio padrão & Mínimo & Máximo & Falcone $^{a}$ & $p^{1}$ \\
\hline \multirow{10}{*}{ Hospital } & \multirow{2}{*}{ DAYSE BREDA } & Masculino & 37 & - & 37 & 37 & 35,40 & \multirow{2}{*}{0,302} \\
\hline & & Feminino & 39,7 & 3,4 & 33 & 45 & 34,19 & \\
\hline & \multirow{2}{*}{ HDT } & Masculino & 37,2 & 2,9 & 34 & 41 & & \multirow{2}{*}{0,659} \\
\hline & & Feminino & 37,8 & 3,2 & 32 & 42 & & \\
\hline & \multirow{2}{*}{ HE } & Masculino & 36,3 & 3,2 & 32 & 42 & & \multirow{2}{*}{0,074} \\
\hline & & Feminino & 38,3 & 6,6 & 13 & 45 & & \\
\hline & \multirow{2}{*}{ HU } & Masculino & 36,8 & 4,5 & 30 & 42 & & \multirow{2}{*}{0,930} \\
\hline & & Feminino & 37,4 & 4 & 29 & 45 & & \\
\hline & \multirow{2}{*}{ SANTA CASA } & Masculino & 31,6 & 13 & 9 & 41 & & \multirow{2}{*}{0,028} \\
\hline & & Feminino & 41,4 & 3,2 & 35 & 44 & & \\
\hline
\end{tabular}

a Valor de referência segundo Falcone 2008; ${ }^{1}$ Teste de Mann-Whitney.

Fonte: Dados da pesquisa.

A Sensibilidade Afetiva (SA), segundo Falcone et al. (2008), reflete-se como sendo um sentimento de compaixão e de interesse pelo estado emocional do outro. Para Araújo (2008, p. 64), "indica uma preocupação genuína diante do bem-estar do outro".

Os integrantes da pesquisa apresentaram valores abaixo do padrão $(43,92)$ se considerados numa avaliação geral (masculino e feminino). Os dados apresentados diferenciados pela variável sexo demonstram, em sua maioria, dados elevados, com uma significativa diferença, de p 0,028, no Hospital Santa Casa, para o sexo feminino com maior valor $(41,4)$ e sexo masculino inferior $(31,6)$, comparados aos dados normativos do IE.

Um estudo apresentou dados semelhantes de SA que correlaciona os valores abaixo dos dados normativos do IE com a dessensibilização do profissional de saúde, para que ele possa tratar sem se envolver emocionalmente. $\mathrm{O}$ conceito de competências e profissionalismo na área ainda permanece impregnado da ideia de que se sensibilizar diante da dor e do sofrimento alheio pode ser prejudicial ao profissional, como se ao ter acesso ao sentimento do outro pudesse perder sua capacidade de autoconhecimento e autocontrole (ARAÚJO, 2008).

Masetti (2001) atenta para o quanto os profissionais de um hospital estão preparados para lidar com as doenças e como a formação acadêmica deles guia os olhares para o que não funciona em um paciente e para se relacionar com isso. Essa autora destaca a transformação paradigmática do trabalho dos Doutores da Alegria: estes artistas focam a atenção naquilo que está saudável. A diferença é sutil, mas se o corpo humano funciona de forma sistêmica, se os medicamentos administrados atuam no organismo de forma sistêmica, seguindo esta lógica, o estímulo à parte saudável de um indivíduo se apresentará de forma sistêmica no organismo. Essa é a essência do trabalho do palhaço de hospital: estimular o que há de saudável em cada pessoa com quem ele se encontra em sua trajetória de atendimentos hospitalares, sejam eles pacientes ou profissionais de saúde. Se por um lado o humor funciona como um agente benéfico aos tratamentos e intervenções, por outro o estresse age como malefício à saúde em geral.

Os profissionais são formados para salvar vidas, favorecer melhorias à saúde do paciente; existe a dificuldade em encarar esse processo contrário como parte integrante da vida, pois esta fragiliza, assusta, trazendo a sensação de impotência (ROCKEMBACH; CASARIN; SIQUEIRA, 2010). Esse quadro ainda presente na formação acadêmica mostra a relevância em ofertar alternativas dentro da formação do profissional de saúde que melhore sua relação com o paciente, ao mesmo tempo que colabore para a transformação da paisagem dos ambientes destinados ao atendimento e ao ensino em saúde. Iniciativas como o Projeto de Extensão Sorriso de Plantão, que têm ganhado espaço nas universidades de Alagoas, mostram o aprendizado para além da patologia. Uma complementaridade importante na formação pessoal e profissional das Instituições de Ensino Superior (IES).

\section{CONSIDERAÇÕES FINAIS}

A análise da pesquisa com o instrumento IE foi satisfatória e obteve como resultado que os participantes do Projeto de Extensão Sorriso de Plantão 
apresentam variáveis compatíveis com os dados normativos. Os integrantes pesquisados demonstram capacidade de enxergar o mundo pelos "olhos" do outro, de aceitar pontos de vista diferentes do seu, de tal maneira que a outra pessoa sinta-se compreendida e validada. $O$ referido projeto, por intermédio de suas atividades, auxilia a resgatar 0 afeto, a sensibilidade na comunicação por meio da formação. Sensibiliza os participantes a adquirir habilidades e competências de comunicação para uma visão integral na assistência ao usuário.

O altruísmo surge como um fator de maior tendência positiva e revela uma maior capacidade de suspender temporariamente as próprias necessidades em função do outro. A sensibilidade afetiva, expressa pelo sentimento de compaixão, revelou-se preocupante quando comparada aos dados normativos do IE. Ao observar o comportamento por sexo percebe-se o gênero feminino mais empático. Os cenários pesquisados podem influenciar quanto ao nível de empatia, embora a maioria demonstre empatia.

Com base nestes pressupostos, e ao considerar as habilidades e competências a serem desenvolvidas no processo de formação em saúde requeridas na Política Nacional de Extensão Universitária, o aluno poderá escolher participar de projetos com os quais se identifique, permitindo-lhe desenvolver os componentes da empatia, bem como contribuir para a formação profissional com o perfil preconizado nas DCNs.

Diante do exposto, pode-se identificar que houve uma limitação do estudo, o que sugere outra pesquisa em que o IE seja aplicado nos alunos ao ingressarem no referido Projeto e após um ano de atuação como palhaço doutor, para que sejam comparados os valores quanto à aquisição de empatia.

\section{REFERÊNCIAS}

ALMEIDA, M. J. et al. Implantação das Diretrizes Curriculares Nacionais na Graduação em Medicina no Paraná. Revista Brasileira de Educação Médica, on-line, v. 31, n. 2, p. 156-165, 2007.

ARAÚJO, C. F. Avaliação da empatia em médicos de diferentes niveis de atenção à saúde. 2008, 92 fl. Mestrado (Dissertação) - Instituto de Psicologia da Universidade Federal do Rio de Janeiro, Rio de Janeiro, 2008.

BARON-COHEN, S. Diferença essencial: a verdade sobre o cérebro de homens e mulheres. Rio de Janeiro: Objetiva, 2004.

BATISTA, N. A.; VILELA, R. Q. B.; BATISTA, S. H. S. S. Educação médica no Brasil. 1. ed. São Paulo, SP: Ed. Cortez, 2015.
BATSON, C. D. Self-other erging and the empathy- altruism hypothesis: reply do Neuberg et al. Journal of Personality and Social Psychology, v. 73, p. 517-522, 1997.

BLAND, J. M.; ALTMAN, D. G. Cronbach's alpha. BMJ, v. 314, p. 572, 1997.

BRASIL. Ministério da Saúde. Secretaria de Gestão do Trabalho e da Educação na Saúde. Departamento de Gestão da Educação na Saúde. Residência Multiprofissional em Saúde: experiências, avanços e desafios. 1. ed. Brasília, DF: MS, 2006.

BRASIL. Ministério da Saúde. Secretaria de Atenção à Saúde. Política Nacional de Humanização da Atenção e Gestão do SUS. Clínica Ampliada e compartilhada. Brasília, DF: MS, 2009. 64 p. (Série B. Textos básicos de saúde).

BRASIL. Ministério da Educação. Parecer CNE/CES 1133/2001 HOMOLOGADO. Despacho do Ministro em 01/10/2001. Diretrizes Curriculares Nacionais dos Cursos de Graduação em Enfermagem, Medicina e Nutrição. Diário Oficial da União, 3/10/2001, Seção 1E, p. 131.

CALDAS, J. B. et al. A percepção de alunos quanto ao programa de educação pelo trabalho para saúde - PET-Saúde. Bras. Edu. Med., v. 36, n. 1, (supl.2), p. 33-41, 2012.

CORREIA, D. S.; TAVEIRA, A. G. M. M.; FREITAS, D. A. Clínica ampliada: as oportunidades de aprendizagem discente no estágio rural em Arapiraca. In: SAMPAIO, J. F., et al. (Org.). A extensão universitária na formação em saúde. Maceió: Edufal, 2015. p. 87-94.

COSTA, F. D.; AZEVEDO, R. C. S. Empatia, relação médico-paciente e formação em medicina: um olhar qualitativo. Rev. Bras. Educ. Med., v. 34, n. 2, p. 261-269, 2010.

CUNHA, G. T. A construção da clínica ampliada na atenção básica. São Paulo: Hucitec, 2010.

ELIOT, L. Cérebro azul ou rosa: o impacto das diferenças de gênero na educação. Tradução Maria Adriana Veríssimo Veronese. Revisão técnica Jane Felipe. Porto Alegre: Penso, 2013. 408p.

FALCONE, E. M. et al. Inventário de empatia: desenvolvimento e validação de uma medida Brasileira. Avaliação Psicológica, v. 7, n. 3, p. 321-334, 2008.

FERREIRA, A. B. H. Mini-Aurélio: Dicionário da Língua Portuguesa. 8. ed. Curitiba. Positivo, 2010.

FORPROEX. Fórum de Pró-Reitores de Extensão das Instituições de Educação Superiores Públicas Brasileiras. Carta de Manaus. ENCONTRO NACIONAL DO FORPROEX, 31., Manaus, 2012.

GONTIJO, E. D.; SENNA, M. I.; FERREIRA, M. F. L. As políticas públicas de avaliação das escolas médicas e as Diretrizes Nacionais Curriculares. In: STREIT, Derly Silva et al. (org.). Educação médica: 10 anos de Diretrizes Curriculares Nacionais. Rio de Janeiro: Associação Brasileira de Educação Médica, 2012. p. 167.

HAMAMOTO FILHO, P. T. Ligas acadêmicas: motivações e críticas a propósito de um repensar necessário. Revista Brasileira de Educação Médica, Rio de Janeiro, v. 35, n. 2, dez. 2011. 
INEP. Instituto Nacional de Estudos e Pesquisas Educacionais Anísio Teixeira. Censo da educação superior 2007. Brasília: Ministério da Educação do Brasil, 2009.

KRZNARIC, R. O poder da empatia: a arte de se colocar no lugar do outro para transformar o mundo. Tradução Maria Luiza X. de A. Borges. 1. ed. Rio de Janeiro: Zahar, 2015.

LEIS, H. R. Sobre o conceito de Interdisciplinaridade. Cadernos de Pesquisa Interdisciplinar em Ciências Humanas, Florianópolis, SC, v. 6, n. 73, ago. 2005.

MARTINS, L. M.; MACIEL, P. P.; PADILHA, W. W. N. Participação do Projeto de Extensão SaBuComu na Formação de Graduandos da Área da Saúde. Revista Brasileira de Ciências da Saúde, v. 19, n. 4, 2015, p. 285-290.

MASETTI, M. Boas misturas: possibilidades de modificações da prática do profissional de saúde a partir do contato com os Doutores da Alegria. 2001. Mestrado (Dissertação) - Pontifícia Universidade Católica de São Paulo, São Paulo, 2001.

MERHY, E. E. A rede básica como uma construção da saúde pública e seus dilemas. In: MERHY, E. E.; ONOCKO, R. (org.). Agir em saúde: um desafio para o público. 2. ed. São Paulo: Hucitec, 2006. p. 197-228.

OLIVEIRA, L. Topofilia: um estudo da percepção, atitudes e valores do meio ambiente. Londrina: Eduel, 2012. 342p.

PEREIRA, L. A.; LOPES, M. G. K.; LUGARINHO, R. Diretrizes Curriculares Nacionais e níveis de atenção à saúde: Como compartilhar? 2006. Disponível em: www.fnespas.org.br. Acesso em: 27 ago. 2017.

PINKER, S. O paradoxo sexual: hormônios, genes e carreira. Rio de Janeiro: Best Seller, 2010.

PORTO, V. F. A. A extensão universitária e a formação profissional em cursos de graduação. 2017. Mestrado (Dissertação) - Faculdade de Medicina Universidade Federal de Alagoas, Maceió, 2017. p. 69.

PORTO, V. F. A.; BITTENCOURT, C. C. B. L. D.; SAMPAIO, J. F. Uma revisão de literatura sobre as contribuições da extensão universitária para a formação profissional em saúde. In: SAMPAIO, J. F. et al. (org.). A extensão universitária na formação em saúde. Maceió: Edufal, 2015. p. 13-22.
RIBEIRO, K. S. Q. S. A contribuição da extensão universitária para formação acadêmica em fisioterapia. Fisioterapia $e$ Pesquisa, v. 12, n. 3, p. 22-29, 2005.

ROCKEMBACH, J. V.; CASARIN, S. T.; SIQUEIRA, H. C. H. Morte pediátrica no cotidiano de trabalho do enfermeiro: sentimentos e estratégias de enfrentamento. Rev. Rene. Fortaleza, v. 11, n. 2, p. 63-71, abr./jun. 2010.

ROSSONI, E.; LAMPERKT, J. Formação profissional para Sistema Único de Saúde e as Diretrizes Curriculares. Bol. Saúde, v. 18, n. 1, p. 87-98, 2004.

RUFINONI, Priscila. Mudanças nos programas educacionais abriram espaço para as mulheres. Portal Brasil. 2015. Disponível em: http://www.brasil.gov.br/educacao/2015/03/ mulheres-sao-maioria-no-ingresso-e-na-conclusao-de-cursos-superiores/mulheres-sao-maioria-no-ingresso-e-na-conclusao-de-cursos-superiores/view. Acesso em: 10 jan. 2017.

SALES, K. N. A. et al. PET-Saúde: formando discentes multiplicadores - relato de experiência. Revista da Abeno, v. 11, n. 2, p. 51-6, 2011.

SILVA, M. R. Projeto Sorriso de Plantão. Disponível em: www.sorrisodeplantao.com.br. Acesso em: 11 ago. 2018.

SILVA, M. R.; SANDES, D. V. O sorriso como recurso terapêutico à criança hospitalizada: lições de palhaços doutores para um cuidado humanizado. Cadernos de Graduação/Ciências Biológicas e da Saúde, v. 3, n. 2, p. 43-56, 2016.

SILVA, M. R.; ROMEIRO, N. S. Sorriso de plantão: a percepção da criança sobre o processo da hospitalização antes e após atuação do palhaço doutor. Cadernos de Graduação/ Ciências Biológicas e da Saúde, v. 3, n. 2, p. 135-148, 2016.

TAKAHAGUI, F. M.; MORAES, E. N. S.; BERALDI, G. H. MadAlegria - estudantes de medicina atuando como doutores-palhaços: estratégia útil para humanização do ensino médico? Revista Brasileira de Educação Médica, Rio de Janeiro, v. 38, n. 1, jan./mar. 2014. 